\title{
Thermal Management of Flat Photovolatic Panels using Serrated Fins to Increase Electrical Output
}

\author{
M. Chandrasekar ${ }^{*}$ and C. Kirthi Priyan
}

\author{
Department of Mechanical Engineering, University College of Engineering, BIT Campus, Tiruchirappalli \\ 620024, India
}

\begin{abstract}
The electrical power output of photovoltaic $(\mathrm{PV})$ cell depends on its operating temperature during its absorption of solar radiation and conversion of solar energy to electrical energy. The increase in PV panel temperature due to overheating negates its electrical yield and efficiency. In addition, overheating causes hot spots, failure of adhesive seals and delamination. An effective way to combat this problem is to reduce the operating temperature of PV panel by cooling. In the present work, a novel thermal management technique for improved cooling of flat PV panel is proposed with the use of serrated fins rather than straight fins. For this reason, the thermal and electrical performance of the flat PV panel with cooling system consisting of duct, brushless DC cooling fan, a plate fin and serrated fins of varying angles $\left(30^{\circ}, 45^{\circ}\right.$ and $\left.60^{\circ}\right)$ made up of aluminium were investigated experimentally. Experiments were conducted at constant wind velocity $(1 \mathrm{~m} / \mathrm{s})$ with the developed technique in the location of Tiruchirappalli (78.6 E to 10.8 N), Tamil Nadu, India with flat $10 \mathrm{~W}$ PV panel. By using serrated fins of varying angles of $30^{\circ}, 45^{\circ}, 60^{\circ}$ and plate fin $\left(90^{\circ}\right)$, the temperature of the $\mathrm{PV}$ panel decreased by a maximum of $4^{\circ} \mathrm{C}, 7^{\circ} \mathrm{C}, 6^{\circ} \mathrm{C}$ and $3^{\circ} \mathrm{C}$ respectively. Similarly the $\mathrm{PV}$ power increased in the range of $15.38 \%, 61.53 \%, 41.53 \%$ and $7.69 \%$ for $30^{\circ}, 45^{\circ}, 60^{\circ}$ and plate fin $\left(90^{\circ}\right)$ respectively. It is concluded that $45^{\circ}$ angled serrated fin is more efficient in providing the cooling effect than the other angles of serrated fins considered.
\end{abstract}

Keywords: Photovoltaic, serrated fin, thermal management, heat transfer, IV characteristics.

\section{INTRODUCTION}

Thermal management is a technique by which the operating temperature of any system is controlled. Thermal management of solar photovoltaic (PV) panels or modules is often suggested to maintain the operating temperature of PV. This is because the actual operating temperature of the $\mathrm{PV}$ is expected to be more under real time outdoor environmental conditions than the normal operating cell temperature (NOCT) which is usually provided by the PV manufacturer under controlled environment. The increase in operating temperature in excess of NOCT results in PV performance degradation and structural degradation. Thermal management options adopted by the researchers for cooling $\mathrm{PV}$ may be generally grouped under passive technique or active technique. A passive thermal regulation technique does not use additional electric power but an active thermal regulation technique uses additional electric power which is termed as parasitic power loss [1]. The various passive and active thermal regulation techniques used for the cooling of PV were listed in Table 1. Though active thermal regulations exhibit lower contact thermal resistance and higher cooling rates, passive techniques are still opted due to various techno-economic reasons like quiet in operations; no or less performance

*Address correspondence to this author at the Department of Mechanical Engineering, University College of Engineering, BIT Campus, Tiruchirappalli 620024, India; Tel: 0431-2407955, +919842031537; Fax: 0431-2407333;

E-mail: shekarpunchu@yahoo.com degradation over time; no operating cost; no risk of operation and eco friendliness $[2,3]$.

Heat transfer by convection mode of heat transfer can be represented as $Q=h A \Delta T$ where $h$ is heat transfer coefficient between the PV panel and atmospheric air under natural convection, $A$ is the surface area available for the heat transfer while $\Delta T$ is difference between the PV panel temperature and the ambient temperature. It can be revealed that $h$ and $\Delta T$ are governed by the environmental conditions but $A$ is system dependent. The surface area can be increased by the introduction of fins which are nothing but extended surfaces attached to the prime surface from which heat transfer has to be improved. In this section, some of the relevant literature on natural cooling of $P V$ panel by using fin is reviewed.

The simplest one involve solids of high thermal conductivity, like aluminum or copper, and an array of fins or other extruded surface to suit the application. More complex systems involve phase change materials and various methods for natural circulation. Tonui and Tripanagnostopoulos [4] studied photovoltaic thermal PVT air collector with a air duct attached behind the PV module with a flat thin metal sheet (TMS) placed in the middle of the air channel and fins attached to the opposite wall of the duct. They found that attaching fins removed substantial heat from the PV surface. Yozwiak and Loxsom [5] developed a cost-effective passive fin cooling system for a roof-mounted PV module made of 
Table 1: Active and Passive Thermal Regulation Techniques Used for the Cooling of PV Panels [2, 3]

\begin{tabular}{|c|c|c|}
\hline Passive techniques & \multicolumn{2}{|c|}{ Active techniques } \\
\cline { 2 - 3 } & Mechanism & Parasitic power \\
\hline \hline Natural cooling by air & Water/liquid cooling underneath PV panel & Pump \\
Buoyancy driven air cooling in ducts & Water spray cooling on the top of PV surface & Pump \\
Heat spreader/Fin cooling & Forced cooling by air & Pump \\
Evaporative cooling & Jet impingement cooling & Pump \\
Phase change material (PCM) cooling & Micro channel cooling & Fan \\
Radiative cooling & Heat pipe - Forced cooling & \\
Submerged cooling & & \\
Heat pipe - Natural cooling & & \\
Wind-driven rooftop turbine ventilator & & \\
\hline
\end{tabular}

aluminum plate that comes in thermal contact with the rear side of a PV module and exposed to the ambient air. They reported a $10^{\circ} \mathrm{C}$ drop in PV operating temperature due to the introduction of fin which corresponded to a $5 \%$ increase in electricity production. This study established that the fin can cool roofmounted PV modules and it was a simple, low-cost solution to temperature degradation during peak sunshine.

In order to reduce the solar cell temperature, 5 numbers of fins were considered at the base of the back plate of a concentrated photovoltaic (CPV) by Sendhilkumar et al. [6] during the development and validation of a thermal model for CPV. The concentration ratio for CPV considered were $5 x$ and 10x. They proved a possibility of reduction in PV cell temperature to an extent of $4^{\circ} \mathrm{C}$ with the inclusion of fin at a focal distance of $50 \mathrm{~mm}$. They also proposed that instead of solid aluminum back plate, a porous hexagonal aluminum mesh with air pores (honeycomb structure) at the top and bottom aluminum plate may be used to observe higher difference between the solar cell temperatures of the system with and without fins. Sendhilkumar et al. [7] also presented a numerical study to predict the cell temperature for the solar PV concentrator with two, three, four and six numbers of rectangular cooling fins. It was concluded that it was not advisable to use more than four fins for the given back plate width. They also recommended using fins of $1 \mathrm{~mm}$ thickness and $5 \mathrm{~mm}$ height.

Abu Rahmeh [8] conducted experiments with 3 different PV cooling methods and assessed the performance of cooled $\mathrm{PV}$ in comparison with the uncooled PV. Cooling methods used were liquid cooing (water and nanofluid) and fin cooling. The author used aluminum rectangular fins during experiments with fin cooling. The maximum improvement in energy conversion was about $1.46 \%$ with fins. Recently, Cabo et al. [9] investigated a passive cooling technique for PV panels which consisted of aluminum fins mounted with epoxy conductive glue on the backside surface of the PV panel. Two specific fin arrangements were considered, namely a parallel positioned solid aluminum fins (L-profile) and a randomly positioned perforated $L$ profiles. The proposed technique was tested on a single PV panel and compared with the reference $P V$, a relative average increase in efficiency of about $2 \%$ was found during peak power.

Selimefendigil et al. [10] experimentally analyzed the performance of solar PV module equipped with porous fins consisting of metal foam which had aluminum or a cellular structure of a metal. The metal foams have very high porosity characteristics with porosity volumes in the range of $75-95 \% .26$ numbers of 6 and $10 \mathrm{~mm}$ thick, $10 \mathrm{~cm}$ length aluminum foams were used. The height of the foam fin was $5 \mathrm{~cm}$. They demonstrated an increase of $7 \mathrm{~W}$ in power output due to the cooling effect caused by the porous fins.

From the literature search, it is evident that the fin cooing is viable option for roof top PV modules. It was also learnt that previous works have reported the optimum number of fins, fin length, fin height, fin arrangements and fin materials. Also it is revealed that effect of serrated fin arrangements has not reported so far. Inclusion of fins result in an increased heat transfer surface area and enhanced heat transfer. However, straight longitudinal fins provide more of a streamline flow of the cooling medium during which the cooling medium normally has lower heat transfer characteristics. On the contrary, serrated fins disturb the fluid flow pattern of the cooling medium causing secondary swirling flow. This swirling flow or the turbulence will further enhance the heat transfer. Therefore in the present work, a novel idea for better 
cooling of flat PV panel is proposed with the use of serrated fins instead of straight fins. In this work, the performance of $\mathrm{PV}$ panel with aluminum serrated fins of varying angles of $30^{\circ}, 45^{\circ}$ and $60^{\circ}$ were investigated and compared with those of plate fin (parallel positioned to the duct $\& 90^{\circ}$ to panel surface) and without fin arrangements.

\section{EXPERIMENTAL TEST FACILITY}

The experimental setup consisted of 2 crystalline 10 Wp solar PV panels. Out of these two PV panels, one is used as a reference panel and the other panel was fitted with fins of different angles at the rear surface of the PV panel. Aluminium sheets of $0.4 \mathrm{~mm}$ thickness were fabricated into 2 numbers of $\mathrm{C}$-channels with 60 $\mathrm{mm}$ height, $80 \mathrm{~mm}$ width and $300 \mathrm{~mm}$ length. Aluminium material was selected due to its light weight, malleability and high thermal conductivity. Each of these $C$ channels were attached to the rear side of the PV panel by applying heat sink compound between the $\mathrm{PV}$ and $\mathrm{C}$-channel to avoid air thermal resistance. This arrangement acted as a plate fins (parallel type) with the protruding portion serving as extended surfaces for enhanced heat transfer. For serrated type fins, the protruding portions were sheared for a length of $40 \mathrm{~mm}$ at an interval of $10 \mathrm{~mm}$ along the $300 \mathrm{~mm}$ length and then bent to the required angle of of $30^{\circ}, 45^{\circ}$ and $60^{\circ}$. The schematic and photographic views of the fabricated fins are shown in Figure 1. The fabricated fins were secured firmly to PV rear surface without sagging with the help of aluminium spike rods. To avoid the influence of atmospheric wind velocity, the air flow was maintained inside a duct placed rear side of the finned PV panel. The reference PV panel was placed over a slot in a supporting surface to facilitate natural cooling. The air flow was simulated with a brushless
DC cooling fan powered by a $12 \mathrm{~V}$ rechargeable battery and the air velocity was maintained at $1 \mathrm{~m} / \mathrm{s}$ using a speed regulator. The duct was fabricated with $0.6 \mathrm{~mm}$ galvanized sheet having a cross section of 290 x $120 \mathrm{~mm}$ and $890 \mathrm{~mm}$ length. Proper insulation was given on the outer surfaces of the duct to avoid heating. PV panel was placed centrally on the top surface of the duct without any surface misalignment. One end was equipped with the fan while the other end was made free from any form of obstacles to act as passage for air outlet. A digital multimeter was used for PV current and voltage measurements from which the power output of the PV module were determined. A rheostat (1-100 $\Omega$ ) was used to vary the load to study I$\mathrm{V}$ characteristics. The temperature of $\mathrm{PV}$ panel rear surface, fin temperature and the ambient temperature were measured by a calibrated K-type thermocouple connected to 6 channel temperature indicator. The wind speed at the duct outlet is measured by an anemometer $(0-30 \mathrm{~m} / \mathrm{s}$ range; $0.1 \mathrm{~m} / \mathrm{s}$ resolution; $\pm 5 \%$ accuracy). Solar irradiation is measured by pyranometer. The details of the experimental test facility are shown in Figures 2 and $\mathbf{3}$. The experimental setup was installed in the roof top of the building of Department of Mechanical engineering, University College of Engineering, BIT campus, Tiruchirappalli. The experiments were carried out during sun shine hours in the months of March and April 2018. The results obtained under clear sky conditions were reported in this article.

\section{RESULTS AND DISCUSSIONS}

\subsection{Thermal Characteristics of the PV Panel}

The thermal characteristics of the PV panel under different arrangements were depicted in Figure 4. It is
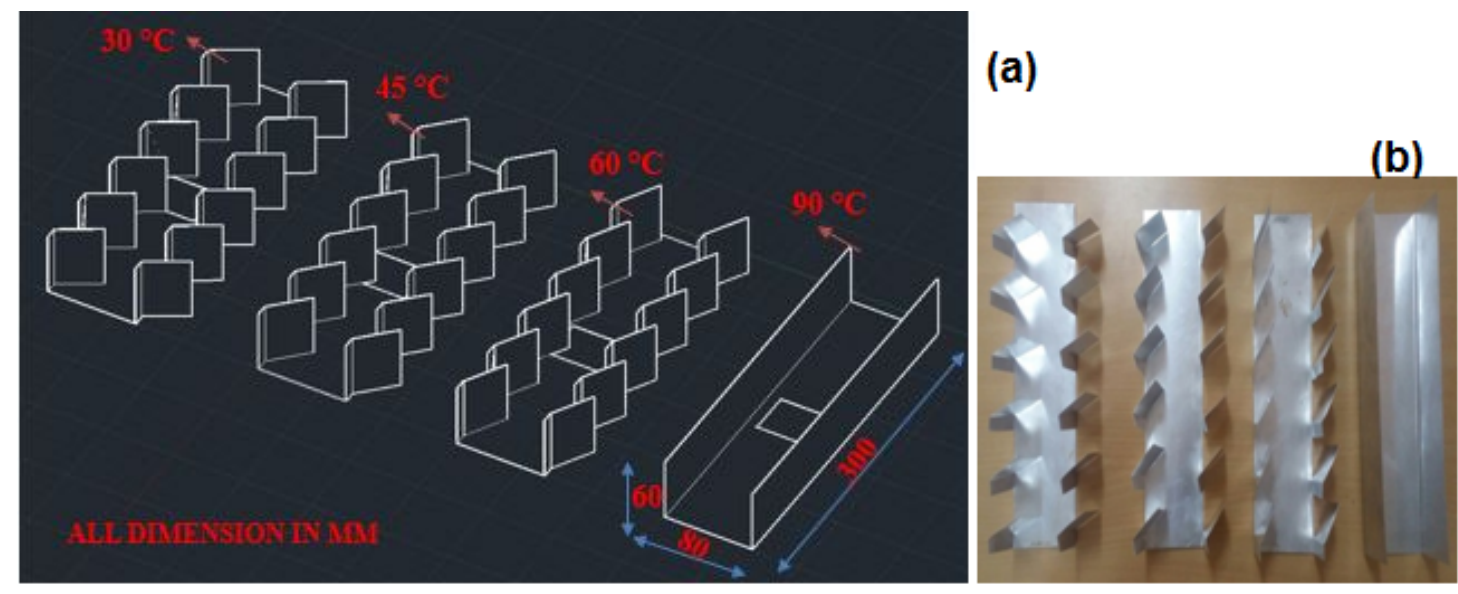

Figure 1: Details of fabricated fins (a) schematic (b) photograph. 

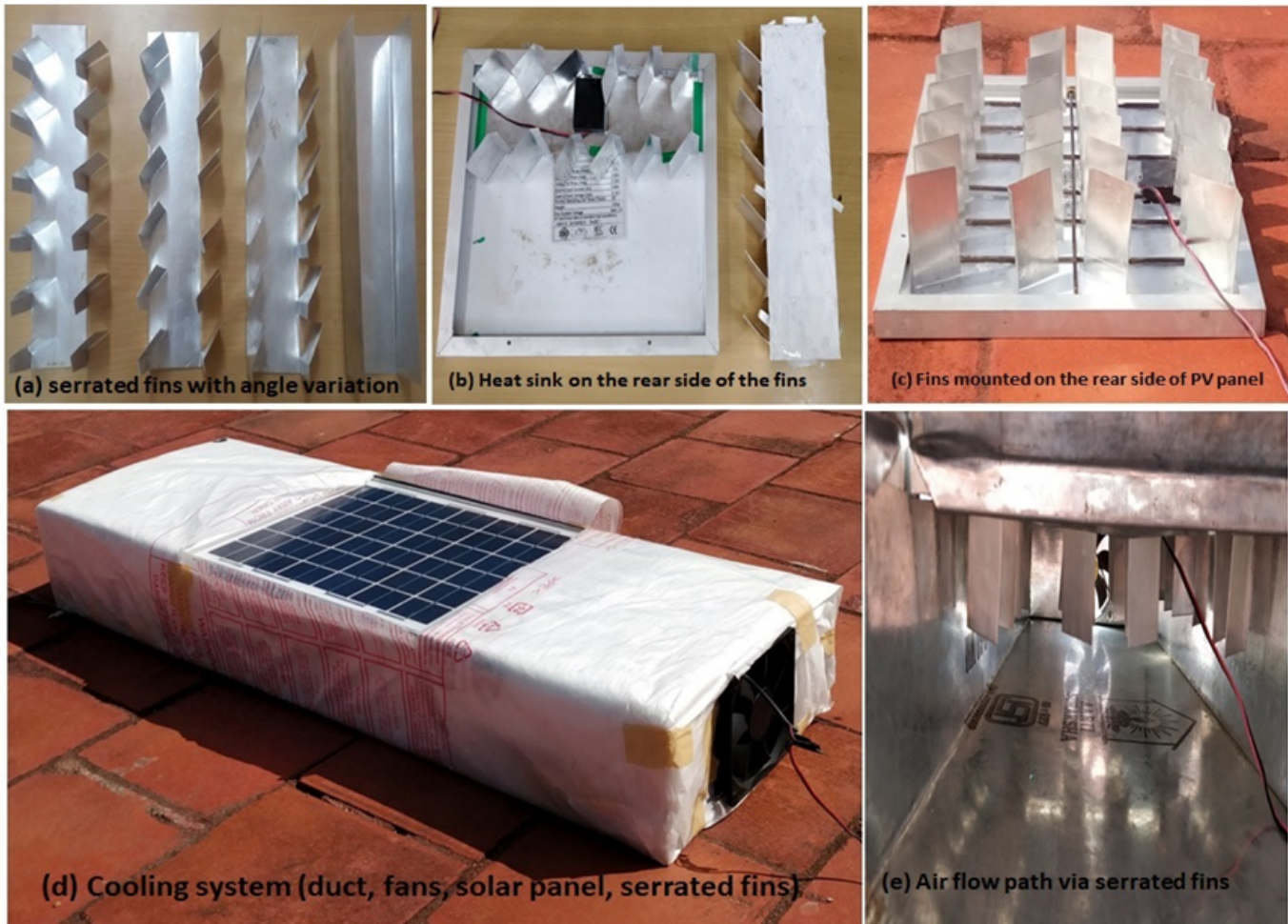

Figure 2: Components of the experimental test facility.

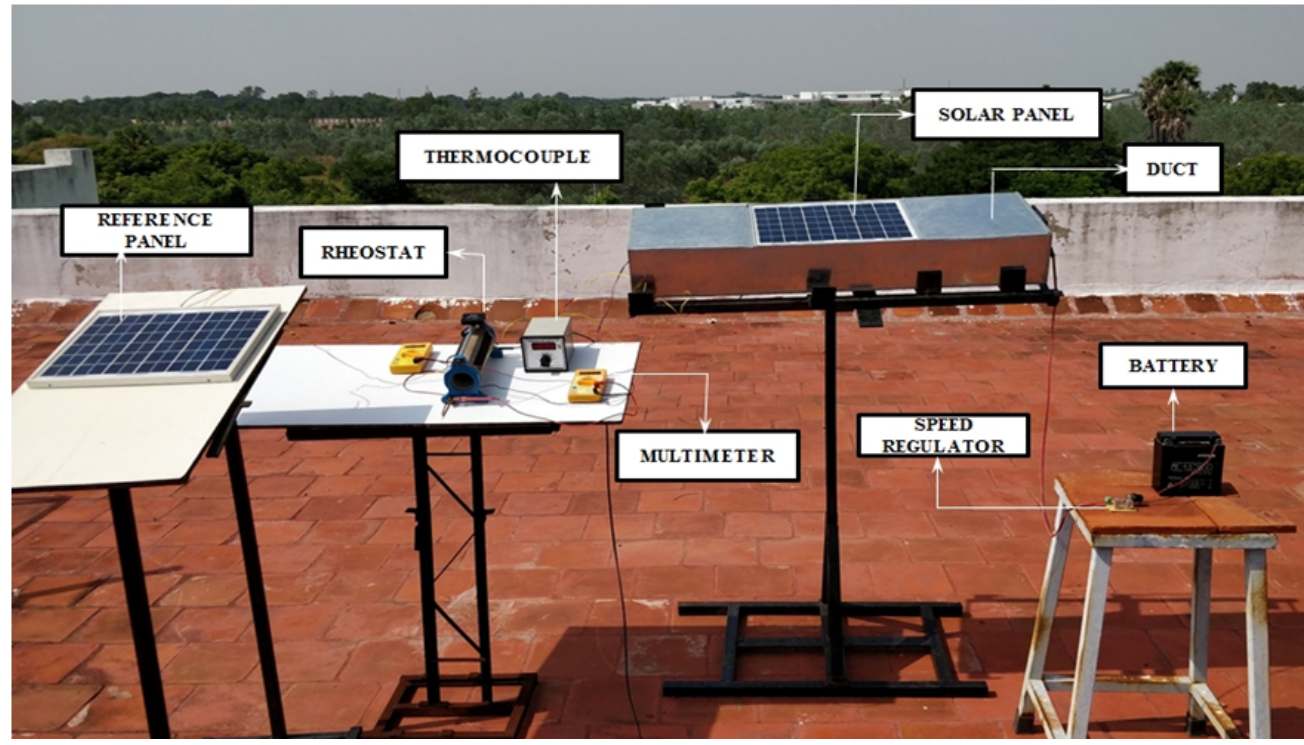

Figure 3: Outdoor experimental test facility.

clear that the temperature of the PV panel without cooling ( $T_{w c}$ ) remained high when compared to the other cases of operation. The maximum temperature of PV panel was observed about $58^{\circ} \mathrm{C}$ during solar noon for the case of without cooling. But, the maximum temperature of $\mathrm{PV}$ panel observed was about $57^{\circ} \mathrm{C}$, $55^{\circ} \mathrm{C}, 54^{\circ} \mathrm{C}$ and $51^{\circ} \mathrm{C}$ during solar noon when PV panel is integrated with plate fin $\left(90^{\circ}\right), 30^{\circ}, 60^{\circ}$ and $45^{\circ}$ serrated fins respectively. It is noteworthy to observe the thermal characteristics of plate fin and without cooling were same especially after the solar noon. This is due to the overheating of fins as the ambient temperature increases after the solar noon. The fin temperature must be lower than the PV surface and must be closer to the ambient temperature for the effective heat transfer. This is a major hurdle in using fins for heat transfer enhancement applications [11]. Compared with the $30^{\circ}$ and $60^{\circ}$ serrated and plate fins, $45^{\circ}$ serrated fin was able to maintain the lowest PV temperature at all time periods. Hence maximum panel 
temperature difference was observed with $45^{\circ}$ serrated fins compared to the case of without cooling.

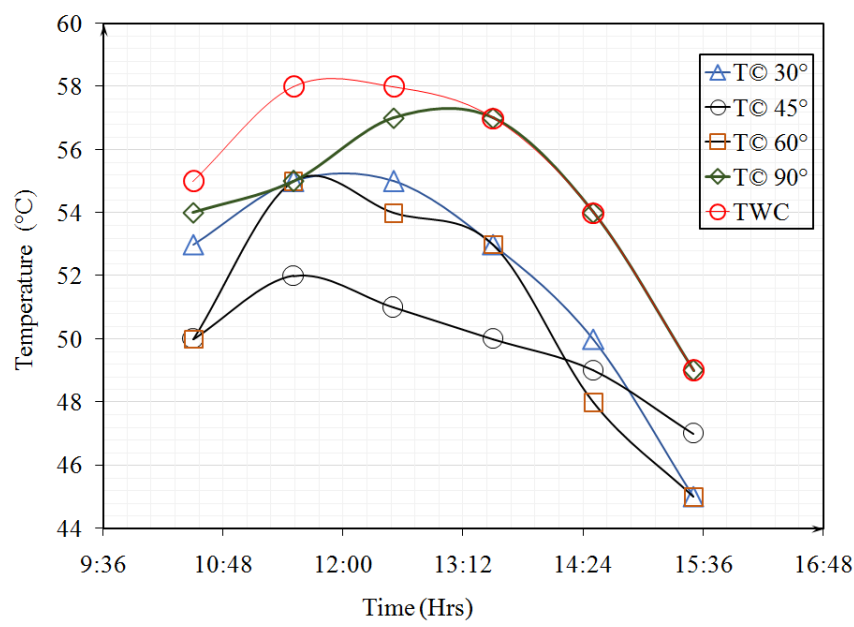

Figure 4: Thermal characteristics of the PV panel under different configurations.

The scientific reason for the attainment of lower PV operating temperature with serrated fins could be due to the creation of flow turbulence with the formation of secondary or vortex flow around the serrated fin portions which cause changes in the air streamline [12]. With plate type fin, the air passes through the passage formed by the fin without any change in its streamline and hence there was no noticeable enhancement in heat transfer and so the temperature of the PV panel was higher. With $45^{\circ}$ serrated fins, maximum disturbances in the streamline would have been taken place to bring the maximum enhancement in heat transfer and the lowest PV temperature. The pictorial representation of the formation of vortex around the serrations was shown in Figure 5. It could be visualized that for a $45^{\circ}$ serrated fins, there will be a maximum possibility for the stream line to deflect more and hence maximum turbulence level could be achieved. This notion is supported by the experimental results that the maximum cooling effect has taken place with $45^{\circ}$ serrated fins. However with $60^{\circ}$ serrated fins, there is a fewer probability for the air streamline to deflect as half of the cross sectional flow area remain unaltered and hence will result in lesser cooling effect. With the case of $30^{\circ}$ serrated fins also there is minimum chance for the stream line to deflect due to high blockage of area of flow.

Fluid flow field was simulated by flowsquare4.0 software to justify the above findings and the results were shown in Figure 6 . For $30^{\circ}$ serrated fins, maximum velocity of air in the flow field was about 3.2 $\mathrm{m} / \mathrm{s}$ and two bigger sized eddies were formed as

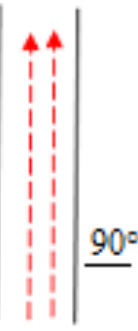

(a)

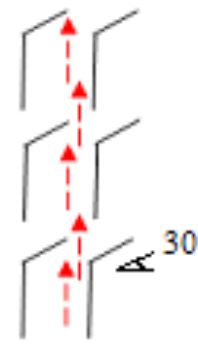

(b)

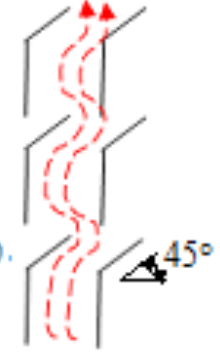

(c)

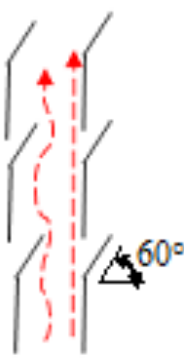

(d)
Figure 5: Pictorial representation of the formation of vortex flow around the serrations (a) plate fin (b) $30^{\circ}$ serrated fin (c) $45^{\circ}$ serrated fin $\left(\right.$ d) $60^{\circ}$ serrated fin.

indicated by concentric circles. For $45^{\circ}$ serrated fins, maximum velocity of air in the flow field was about 2.2 $\mathrm{m} / \mathrm{s}$ and smaller sized eddies were formed at the bends and tip of the fins. Similarly with $60^{\circ}$ serrated fins, the maximum flow flied velocity is limited to $1.67 \mathrm{~m} / \mathrm{s}$ and eddy formations were incomplete as noticed by bigger sized eddies. Under constant mass flow rate, maximum flow field velocity occurred with $30^{\circ}$ serrated fins due to the heavy area blockage which result in lesser free flow area. Hence it is suggested that $45^{\circ}$ serrated fins may be the optimized configuration from the point of view of the thermal characteristics of PV panel.

\subsection{Electrical Characteristics of the PV Panel}

The electrical power output of the PV panel while operating under different configurations with respect to the time was shown in Figure 7. The power output is increased with cooling of the PV panel. Maximum power produced was $10,9,8,6.5$ and $6 \mathrm{~W}$ with $45^{\circ}$, $60^{\circ}, 30^{\circ}$ serrated fins, plate fin and without cooling respectively. As maximum cooling has taken place with the $45^{\circ}$ serrated fins, power output is maximized with this case. The temperature coefficient for power has been found as $0.5 \mathrm{~W} /{ }^{\circ} \mathrm{C}, 0.66 \mathrm{~W} /{ }^{\circ} \mathrm{C}, 0.75 \mathrm{~W} /{ }^{\circ} \mathrm{C}$ and $0.57 \mathrm{~W} /{ }^{\circ} \mathrm{C}$ respectively for the cases of $\mathrm{PV}$ with plate fin, $30^{\circ}, 60^{\circ}$ and $45^{\circ}$ serrated fins. To probe further with the reason for the increase in power with cooling, I-V characteristics were plotted during the solar noon (Figure 8). It is inferred that the increases in both the short circuit current and open circuit voltage were responsible for the increase in power output generated by PV with cooling arrangements. It is also observed that the increase in short circuit current is more than the increase in open circuit voltage. Moreover, the squareness of the I-V curve indicates the measure of fill factor (defined as $F F=\frac{I_{m} V_{m}}{I_{s c} V_{o c}}$ ) and represents the percentage of actual power produced from the maximum possible. From Figure 8, the values of $I_{m}, V_{m}$, $I_{s c}$ and $V_{o c}$ are taken (highlighted only for $45^{\circ}$ serrated 

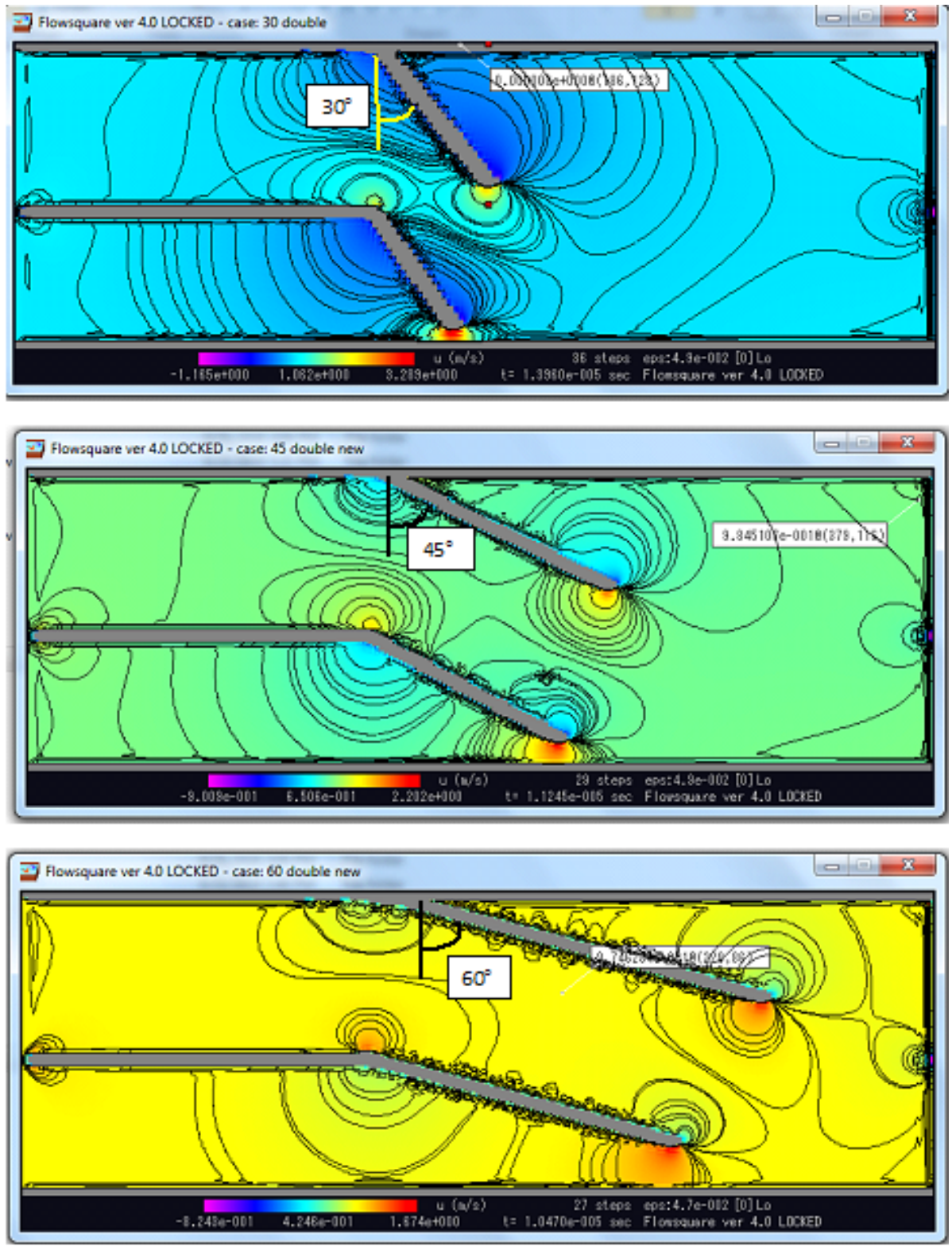

Figure 6: Simulated results of air flow field with serrated fins.

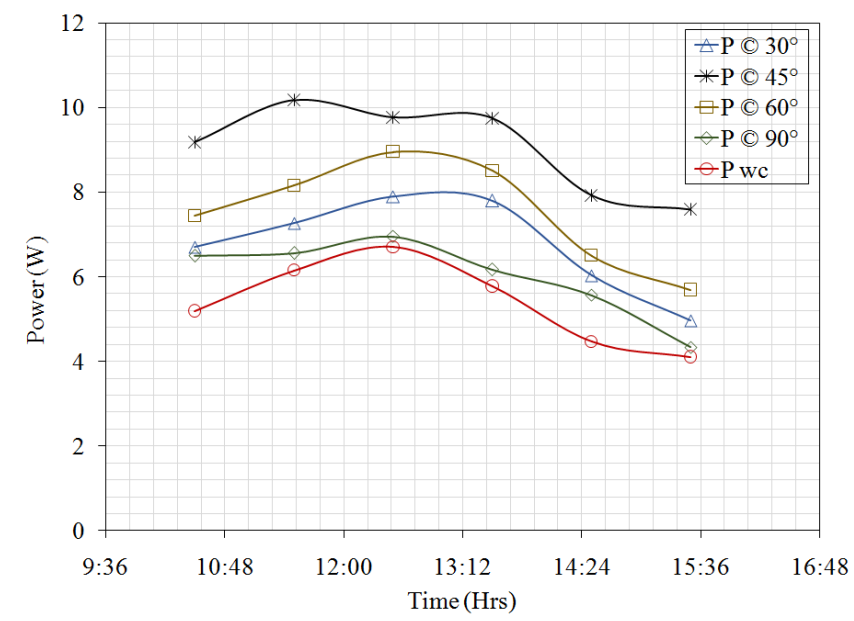

Figure 7: Power output comparison under different configurations.

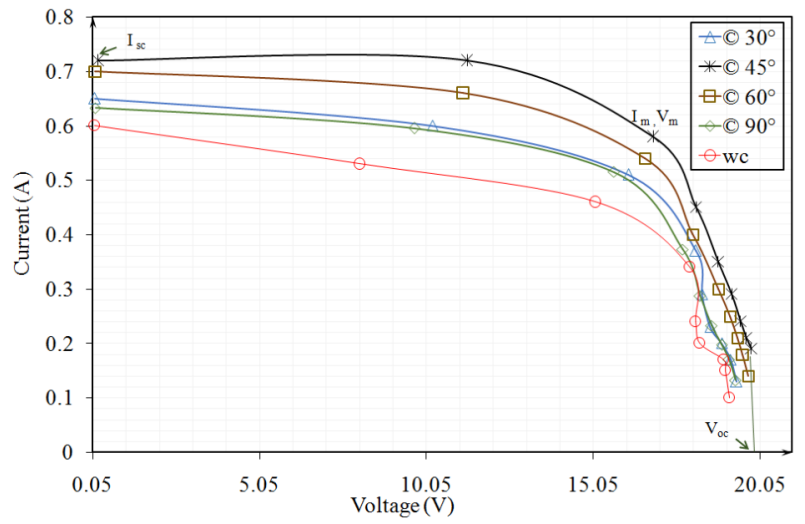

Figure 8: I-V characteristics.

fins for clarity) and the fill factors were calculated as 0.6 for the case of without cooling; 0.73 for $30^{\circ}$ and 
$60^{\circ}$ serrated fins; 0.68 for $45^{\circ}$ serrated fins. These results reveal that the squareness of IV curve improves with cooling arrangement and suggests the proposed designs of serrated fins are capable of approaching the maximum limit of power produced.

\section{CONCLUSIONS}

In this work, serrated fins were used on the rear side of $\mathrm{PV}$ panel to enhance heat dissipation from the PV surface by avoiding undesirable overheating and power production loss. For this purpose, the effect of serration angles on the cooling effect and power yield of the PV panel was investigated experimentally. The following were the conclusions drawn from the present work.

(i) Compared with the plate fins, $30^{\circ}$ and $60^{\circ}$ serrations, $45^{\circ}$ serrated fin was able to maintain the lowest $\mathrm{PV}$ temperature at all time periods. A maximum difference of $7{ }^{\circ} \mathrm{C}$ was observed with $45^{\circ}$ serrated fins compared with the case of without cooling. The formation of flow turbulence due the secondary or vortex flow around the serrated fin portions was the reason for enhanced cooling.

(ii) Due to reduced operating $\mathrm{PV}$ temperatures $\left(51^{\circ} \mathrm{C}\right)$ with $45^{\circ}$ serrated fin against $58^{\circ} \mathrm{C}$ with no cooling arrangement, the maximum electrical power yield of $\mathrm{PV}$ panel with $45^{\circ}$ serrated fin was $10 \mathrm{~W}$ against $6 \mathrm{~W}$ with no cooling arrangement.

Based on the present experimental investigation, it is concluded that the optimized angle of fin angle serration is $45^{\circ}$ for better thermal and electrical characteristics of PV panel.

\section{ACKNOWLEDGEMENTS}

The authors acknowledge Technical Education Quality Improvement Program (TEQIP) phase II for granting Research Seed Money for carrying out this research work. The authors also thank the anonymous reviewers for their valuable comments in improving the quality of the manuscript.

\section{NOMENCLATURE}

$$
\begin{aligned}
& \mathrm{FF}=\text { Fill factor } \\
& \mathrm{I}_{\mathrm{m}}=\text { Maximum current }(\mathrm{A}) \\
& \mathrm{I}_{\mathrm{sc}}=\text { Short circuit current }(\mathrm{A})
\end{aligned}
$$

$\mathrm{P} \quad=\mathrm{PV}$ power with cooling $(\mathrm{W})$

$\mathrm{P}_{\mathrm{Wc}}=\mathrm{PV}$ power without cooling $(\mathrm{W})$

$\mathrm{T}=\mathrm{PV}$ panel temperature with cooling $\left({ }^{\circ} \mathrm{C}\right)$

$\mathrm{T}_{\mathrm{Wc}}=\mathrm{PV}$ panel temperature without cooling $\left({ }^{\circ} \mathrm{C}\right)$

$\mathrm{V}_{\mathrm{m}}=$ Maximum voltage $(\mathrm{V})$

$\mathrm{V}_{\mathrm{oc}}=$ Open circuit voltage $(\mathrm{V})$

$W C=$ Without cooling

\section{REFERENCES}

[1] Shukla A, Kant K, Sharma A, Biwole PH. Cooling methodologies of photovoltaic module for enhancing electrical efficiency: A review Solar Energy Materials \& Solar Cells 2017; 160: 275-286. https://doi.org/10.1016/j.solmat.2016.10.047

[2] Chandrasekar M, Rajkumar S, Valavan D. A review on the thermal regulation techniques for non integrated flat PV modules mounted on building top. Energy and Buildings 2015; 86: 692-697. https://doi.org/10.1016/i.enbuild.2014.10.071

[3] Royne A, Dey CJ. Design of a jet impingement cooling device for densely packed PV cells under high concentration. Solar Energy 2007; 81:1014-1024. https://doi.org/10.1016/j.solener.2006.11.015

[4] Tonui JK, Tripanagnostopoulos Y. Performance improvement of $\mathrm{PV} / \mathrm{T}$ solar collectors with natural air flow operation. Solar Energy 2008; 82: 1-12. https://doi.org/10.1016/j.solener.2007.06.004

[5] Yozwiak M, Loxsom, F. Passive cooling of roof-mounted photovoltaic modules. Conference Proceedings of American Solar Energy Society SOLAR 2010. Experimental validation of a heat transfer model for concentrating photovoltaic system. 2010.

[6] Sendhil Kumar N, Matty K, Rita E, Simon W, Ortrun A, Alex C, Roland W, Tim G, Tapas Kumar M. Experimental validation of a heat transfer model for concentrating photovoltaic system. Applied Thermal Engineering 2012; 3334: 175-182.

https://doi.org/10.1016/j.applthermaleng.2011.09.031

[7] Sendhil Kumar N, Tapas Kumar M, Matty K, Simon W. Numerical investigations of solar cell temperature for photovoltaic concentrator system with and without passive cooling arrangements. International Journal of Thermal Sciences 2011; 5: 2514-2521.

[8] Abu-Rahmeh TM, Efficiency of Photovoltaic Modules Using Different Cooling Methods: A Comparative Study. Journal of Power and Energy Engineering 2017; 5: 32-45. https://doi.org/10.4236/jpee.2017.59003

[9] Cabo FG, Nizetic S, Coko D, Kragic IM, Papadopoulos A Experimental investigation of the passive cooled freestanding photovoltaic panel with fixed aluminum fins on the backside surface. Journal of Cleaner Production 2018; 76 : 119-129.

https://doi.org/10.1016/j.jclepro.2017.12.149

[10] Selimefendigil F, Bayrak F, Oztop H.F. Experimental analysis and dynamic modeling of a photovoltaic module with porous fins. Renewable Energy 2018; 125: 193-205. https://doi.org/10.1016/j.renene.2018.02.002 
[11] Solanki CS, Sangani CS, Gunashekar D, Antony G. Enhanced heat dissipation of V-trough PV modules for better performance, Solar Energy Materials and Solar Cells 2008; 92: $1634-1638$.

https://doi.org/10.1016/j.solmat.2008.07.022
[12] Hashizume K, Morikawa R, Koyama T, Matsue T. Fin efficiency of serrated fins, Heat Transfer Engineering 2002; 23: 6-14.

https://doi.org/10.1080/01457630252800386 